\title{
Turismo de base comunitária em Unidades de Conservação: justiça ambiental para o desenvolvimento local
}

\author{
Community-based tourism in Protected Areas: environmental justice \\ for local development
}

\section{Patrícia Betti, Valdir Frigo Denardin}

\begin{abstract}
RESUMO
A possibilidade de terceirização de serviços de apoio à visitação e ao turismo em unidades de conservação (UCs) vem sendo indicada como uma das soluções para viabilizar o uso público nestes espaços, sendo possível privilegiar médios e grandes empresários ou valorizar e inserir as populações locais neste processo. Com o objetivo de melhor compreender a relação entre turismo de base comunitária (TBC) e UCs, realizou-se pesquisa bibliográfica. O resultado demonstrou que a necessidade de criação destes espaços protegidos insere-se num contexto global de crise socioambiental, consequência do modelo de desenvolvimento hegemônico, e que o estabelecimento destas UCs afeta grupos sociais desigualmente. Por um lado, os serviços ambientais prestados são estendidos em nível global, como na absorção de gás carbônico, por exemplo. Por outro lado, as populações locais são mais impactadas por restrições a atividades econômicas e culturais, decorrentes da legislação ambiental. Conflitos pelo uso de recursos naturais como este, que nascem da crescente utilização do ambiente natural devido à expansão econômica, que avança e causa ressentimentos em territórios já habitados por outras pessoas e espécies, originaram o movimento pela justiça ambiental. Neste movimento ecologista o principal não é a reverência sagrada à natureza, mas um interesse material pelo meio ambiente para a própria subsistência. Em algumas categorias de UCs o ecoturismo é uma das poucas atividades econômicas permitidas, por vezes a alternativa restante aos moradores locais. Desta maneira, sua vinculação ao turismo de base comunitária, capaz de contribuir para a consolidação de dimensões do trabalho, social, política, cultural, ambiental e humana e da própria expressão da dimensão simbólica da vida em sociedade, favorece o desenvolvimento local sustentável, um dos objetivos do Sistema Nacional de Unidades de Conservação da Natureza, proposta que inclui, além de benefícios econômicos e sociais, a valorização da cultura, dos modos de vida, das tradições e das cosmologias locais.
\end{abstract}

PALAVRAS-CHAVE: Unidades de Conservação; Turismo de Base Comunitária; Desenvolvimento Local; Justiça Ambiental. 
Betti, P.; Denardin, V.F.

\begin{abstract}
The possibility of outsourcing the services to support visitation and tourism in protected areas has been recommended as a solution to enable the public use of these spaces and can focus on medium and large businesses or enhance and insert local populations. With the aim of a deeper understanding of the relationship between community-based tourism and protected areas, a bibliographical interdisciplinary research was performed. The result showed that the need for the creation of these protected areas is part of a context of global environmental crisis, the effect of the prevailing model of development, and that the establishment of these areas affects social groups unequally. On the one hand, the environmental services are extended globally, as the absorption of carbon dioxide, for example. On the other hand, local populations are more impacted by restrictions on economic and cultural activities arising from environmental legislation. Conflicts over the use of natural resources such as this, arise from the increasing use of the natural environment due to economic expansion, which causes resentment in areas already inhabited by people and other species, originated the environmental justice movement. In this environmental movement the principal is not the holy reverence to nature, but a material interest in the environment for subsistence. In some categories of protected areas ecotourism is one of the few economic activities allowed, sometimes remaining alternative to local residents. In this context, community-based tourism, able to contribute to the consolidation of dimensions of work, social, political, cultural, environmental, human and symbolic dimension of life in society, promotes local sustainable development, one of the goals of Brazilian National System of Conservation Units Law, a proposal which includes, in addition to economic and social benefits, appreciation of culture, ways of life, traditions and local cosmologies.
\end{abstract}

KEYWORDS: Protected Areas; Community-Based Tourism; Local Development; Environmental Justice.

\title{
Introdução
}

A proteção de áreas naturais é uma medida utilizada para preservação de espécies em larga escala, comunidades biológicas e a manutenção de serviços ambientais tais como água, ar e alimentos, essenciais à sobrevivência de todos os seres vivos, e passou a ser defendida diante dos impactos causados no ambiente natural pela espécie humana. No Brasil, entre as áreas legalmente protegidas encontram-se as unidades de conservação, cujos objetivos compreendem promover o desenvolvimento sustentável a partir dos recursos naturais seguindo-se princípios e práticas de conservação.

Para conquistar adeptos à causa ambiental o turismo é recorrentemente utilizado como argumento, principalmente em áreas que já sofrem pelo pouco desenvolvimento econômico, baseando-se nos benefícios potenciais desta atividade para a conservação e utilização sustentável da natureza. No entanto, o cumprimento deste e demais objetivos do Sistema Nacional de Unidades de Conservação enfrenta diferentes obs- 
Turismo de base comunitária em Unidades de Conservação: justiça ambiental para o desenvolvimento local

táculos na implementação e gestão destas UCs, dentre os quais estão os baixos orçamentos públicos destinados ao meio ambiente.

Como uma das soluções para viabilizar a visitação nestes espaços vem sendo indicada a terceirização de serviços de apoio ao uso público através de instrumentos de gestão tais quais autorização, permissão, concessão e gestão compartilhada. Estas modalidades permitem a participação de populações locais, organizações não governamentais e iniciativa privada na prestação de serviços de apoio à visitação e ao turismo.

Diante deste contexto, com o objetivo de melhor compreender a relação entre turismo de base comunitária e as unidades de conservação, foi realizada pesquisa bibliográfica. Na primeira seção do texto a seguir aborda-se como a atividade turística possibilita o desenvolvimento territorial/local a partir de lógicas não hegemônicas. $\mathrm{Na}$ seção seguinte discorre-se a respeito dos conflitos gerados a partir da criação de UCs e do turismo como potencial de desenvolvimento socioeconômico neste cenário. A terceira seção trás reflexões sobre a terceirização de serviços como uma das soluções para promover a visitação nas UCs. Na quarta e última seção são apresentadas características do turismo de base comunitária e sua relação ao movimento de justiça ambiental, que nasce de conflitos sociais pelo uso de recursos naturais enquanto fonte de subsistência.

Por último, nas considerações finais são apresentados alguns apontamentos sobre os alcances mais sustentáveis na congruência entre turismo de base comunitária e desenvolvimento local para enfrentamento da crise socioambiental instalada.

\section{Turismo: valorização local e desenvolvimento}

O desenvolvimento correntemente é associado a uma ideia de progresso em que a ampliação de riquezas materiais e geração de bem estar e conforto levariam à satisfação das necessidades humanas. Esta concepção compreendida como crescimento econômico surge na metade do século XX, após a Segunda Guerra Mundial, em um clima favorável ao chamado "desenvolvimentismo", guiado pela industrialização e urbanização. Mais de meio século depois se observa que o modelo de desenvolvimento baseado no aumento constante da riqueza econômica e na competitividade entre mercados, desconsiderando a importância das dimensões sociais e ambientais, gerou a crise socioambiental contemporânea. Os resultados positivos prometidos foram alcançados apenas por alguns países e para uma parte das pessoas, e os impactos negativos da degradação ambiental foram externalizados para toda sociedade.

Diante destas observações, Furtado (1974) definiu o desenvolvimento econômico como um mito, uma vez que não é garantido apenas com crescimento econômico. Nas palavras de Furtado, "desenvolvimento não é apenas um processo de acumulação e de aumento de produtividade macroeconômica, mas principalmente o caminho de acesso a formas sociais mais aptas a estimular a criatividade humana e responder às aspirações da coletividade" (FURTADO, 2004, p.485). O crescimento econômico "vem se fundando na preservação dos privilégios das elites que satisfazem seu afã de modernização; já o desenvolvimento se caracteriza pelo seu projeto social subjacen- 
te" (FURTADO, 2004, p.484). Em suma, o crescimento econômico por si só não proporciona desenvolvimento como consequência sem que haja vontade política organizada para a ação no sentido de estender os frutos em um projeto social.

Além de induzir modificações socioeconômicas e ambientais para melhorar a renda, a qualidade de vida e o bem-estar das populações, entendendo que "todo processo de desenvolvimento tem, inexoravelmente, um sentido societário", o desenvolvimento deve incluir processos de mudança social, ampliação da justiça social, das liberdades individuais e da emancipação política (SCHNEIDER; PEYRÉ TARTARUGA, 2004, p.14). No meio rural, por exemplo, a busca por alternativas para territórios submetidos a impactos como modernização da agricultura, desigualdades regionais, limitações impostas pela legislação ambiental, dentre outros fatores, impele seus atores à diversificação de suas atividades como estratégia de adaptação às novas realidades. A atividade turística de base comunitária, ao passo que valoriza pessoas e recursos locais, tem se apresentado como oportunidade de resgate dos vínculos com o território, fortalecimento da identidade e diversidade sociocultural e possibilitado o desenvolvimento territorial/local a partir de lógicas de desenvolvimento não hegemônicas, numa perspectiva multidimensional - social, ambiental, cultural e econômica.

Em se tratando de áreas naturais protegidas, localizadas significativamente no espaço rural, o desafio principia no fato de que, não raramente, a ideia de conservação ambiental é associada à ideia de impedimento ao desenvolvimento. Por outro lado, na defesa à proteção de amostras de ecossistemas em áreas legalmente protegidas tais como unidades de conservação (UCs) observam-se lacunas que contribuem para esse entendimento equívoco. Visto que a criação e gestão de UCs não envolve somente a preservação de recursos naturais, mas a manutenção de grupos sociais que vivem, trabalham e buscam sua reprodução sociocultural, os direitos destas pessoas também devem ser preservados neste processo.

Para conquistar adeptos à causa ambiental entre as populações habitantes em áreas de abrangência de UCs recorrentemente o turismo é apontado como alternativa de desenvolvimento local, principalmente em áreas que já sofrem pelo pouco desenvolvimento econômico, baseando-se nos benefícios que esta atividade potencialmente desencadeia para a conservação e utilização sustentável da natureza. Ressalta-se, no entanto, que apesar da "marca" de uma unidade de conservação ser capaz de valorizar territórios e atrair demanda turística ela por si só não garante a extensão destes benefícios à população local, sem que haja um projeto social de desenvolvimento do turismo com base local, mais justo e equitativo.

\section{Conservar para desenvolver: o papel das Unidades de Conservação}

Diante dos impactos causados no ambiente natural pela espécie humana, a proteção de áreas naturais passou a ser utilizada como forma possível na preservação de espécies em larga escala, comunidades biológicas e a manutenção de serviços ambientais essenciais à sobrevivência de todas as espécies, tais como água, ar e alimentos (DOUROJEANNI; PÁDUA, 2007; PRIMACK; RODRIGUES, 2002). No Brasil, entre as áreas legalmente protegidas encontram-se as unidades de conservação, com 
Turismo de base comunitária em Unidades de Conservação: justiça ambiental para o desenvolvimento local

regras próprias de manejo ${ }^{1}$ e definição legal para sua criação, entendidas como:

Espaço territorial e seus recursos ambientais, incluindo as águas jurisdicionais, com características naturais relevantes, legalmente instituído pelo Poder Público, com objetivos de conservação e limites definidos, sob regime especial de administração, ao qual se aplicam garantias adequadas de proteção (Art.2 ${ }^{\circ}$ inciso I, da Lei 9.985, de 18 de julho de 2000).

O domínio de uma UC pode ser público ou privado, admitir ou não a presença de populações em seu interior, e permitir ou não a visitação pública, questões que variam de acordo com a categoria da UC e respeitando-se normas específicas de cada unidade, definidas em seu plano de manejo ${ }^{2}$ e legislação pertinente. O Sistema Nacional de Unidades de Conservação da Natureza - SNUC é constituído pelo conjunto das UCs federais, estaduais e municipais, divididas em dois grupos: as de uso sustentável $^{3}$, as quais aprovam o uso direto de parte dos recursos naturais; e as de proteção integral $^{4}$, que permitem apenas o uso indireto ${ }^{5}$.

A criação de unidades de conservação gera nova dinâmica de apropriação dos espaços e dos recursos naturais de uso comum do território ${ }^{6}$ no qual se inserem. Por um lado, podem proporcionar benefícios como a preservação dos recursos naturais necessários para a subsistência das populações, garantia de direitos às comunidades tradicionais, barreira à especulação imobiliária, implementação de políticas públicas, etc. Por outro lado, podem implicar impactos negativos quando, por exemplo, não são realizados estudos prévios aprofundados, não há implementação das UCs, existe restrição de práticas econômicas e culturais, a população local é realocada e/ou não é inserida no processo de criação e gestão destas áreas, entre outros fatores. Nestes casos, conflitos socioambientais são gerados e por vezes a comunidade se coloca em oposição às unidades por sentirem seus direitos cerceados.

Diante da importância natural, sociocultural e econômica dos espaços territoriais das UCs, seu planejamento e gestão de modo a conservarem a diversidade natural e sociocultural, os serviços ambientais e ainda propiciarem desenvolvimento local é um desafio. De acordo com Leuzinger (2007), as UCs devem conciliar os direitos culturais àqueles naturais de maneira a prover à sociedade um meio ambiente equilibrado:

Não se contesta, portanto, a necessidade de instituição de unidades de conservação, incluídas as UCs de proteção integral e domínio público, como necessárias à proteção do ambiente natural e, em especial, da diversidade biológica, mas defende-se que sua instituição deve obedecer aos requisitos constitucionais e infraconstitucionais, que permitem conciliar o direito ao meio ambiente ecologicamente equilibrado e os direitos culturais, dentro da perspectiva de ser o Brasil não apenas um país rico em biodiversidade, mas também um país sociodiverso, portador de imensa riqueza cultural, que conforma o seu patrimônio cultural, essencial à formação da identidade nacional (LEUZINGER, 2007, p.307). 
Entre os objetivos do SNUC consta promover o desenvolvimento sustentável a partir dos recursos naturais utilizando-se princípios e práticas de conservação (Lei 9.985, de 18 de julho de 2000). As UCs do grupo de uso sustentável possibilitam maior gama de atividades econômicas, incluindo extrativismo, manejo florestal e caça, de acordo com a categoria e respectivo plano de manejo da unidade. Já em UCs do grupo de proteção integral permite-se apenas o uso indireto dos recursos naturais, acarretando maiores mudanças nos modos de vida das populações.

Neste cenário em que a visitação turística é comportada na maioria das categorias de UCs (com exceção apenas das estações ecológicas e das reservas biológicas) (LEUZINGER, 2010), em algumas destas o ecoturismo é uma das poucas atividades econômicas permitidas, por vezes a alternativa restante às populações locais, e pode ser definido da seguinte maneira:

Ecoturismo é o segmento da atividade turística que utiliza, de forma sustentável, o patrimônio natural e cultural, incentiva sua conservação e busca a formação de uma consciência ambientalista por meio da interpretação do ambiente, promovendo o bem-estar das populações (BRASIL, 1994).

Ao abranger em sua conceituação a conservação da natureza, a educação e a interpretação ambiental, a valorização cultural e o desenvolvimento local, o ecoturismo, ou turismo ecológico, torna-se compatível às unidades de conservação, desde que previsto e respeitando-se as normas do plano de manejo e do plano de uso público da unidade em questão (KINKER, 2005).

\section{Ecoturismo nas Unidades de Conservação}

Apesar do significativo potencial que a diversidade de ecossistemas e paisagens aliadas à riqueza cultural apresenta para o ecoturismo, a participação brasileira é ainda muito pequena neste segmento (KINKER, 2005). De acordo com Kinker (2005), o estímulo ao desenvolvimento das atividades de uso público nas áreas protegidas, tais como visitação, recreação e turismo, tem sido impulsionado recentemente por tendências mundiais, financiamentos de agências de cooperação e bancos internacionais e pela pressão nacional para que as UCs de fato promovam desenvolvimento territorial. Neste sentido, o documento "Diretrizes para visitação em unidades de conservação", elaborado pelo Ministério do Meio Ambiente (MMA, 2006) ressalta a importância do planejamento da visitação ${ }^{7}$ no SNUC de modo a "cumprir os objetivos de sua criação, além de funcionar como uma ferramenta de sensibilização da sociedade sobre a importância da conservação da biodiversidade e como um vetor de desenvolvimento local e regional" (MMA, 2006, p.7).

O estudo "Contribuição das unidades de conservação brasileiras para a economia nacional" (MEDEIROS et al., 2011) afirma que, apenas nos parques nacionais, o incentivo à visitação tem potencial para gerar entre $R \$ 1,6$ bilhão e $R \$ 1,8$ bilhão por ano na economia nacional, considerando as estimativas de fluxo de turistas projeta- 
das para o país até 2016, ano das Olimpíadas (cerca de 13,7 milhões de pessoas, entre brasileiros e estrangeiros). No ano dos Jogos Olímpicos estas UCs injetariam até $\mathrm{R} \$ 2,2$ bilhões na economia a partir de ganhos obtidos com ingressos, parcerias e geração de renda nas populações do entorno, desde que, no entanto, haja investimentos significativos. Porém, na prática observa-se justamente diminuição destes investimentos. Entre 2001 e 2010 a verba destinada às unidades federais manteve-se a mesma, cerca de $\mathrm{R} \$ 300$ milhões por ano. No entanto, no mesmo período a área total protegida aumentou $83,5 \%$. O investimento em cada hectare conservado pelo governo brasileiro, portanto, sofreu uma redução de $40 \%$ desde o início da década passada (MEDEIROS et al., 2011). Este valor foi complementado, em parte, por recursos de compensação ambiental $^{8}$, o qual proporcionou $R \$ 33,4$ milhões para os parques nacionais entre janeiro e junho de 2013 (O GLOBO, 2013a).

Em 2010, quando realizado o estudo anteriormente citado, existiam 67 parques nacionais, dos quais apenas dezoito apresentavam visitação estruturada considerada satisfatória, com controle do fluxo de visitantes e cobrança de ingressos (MEDEIROS et al., 2011). Atualmente são 69 parques nacionais e o cenário pouco se modificou. Faltam serviços como centro de visitantes, mapas, lanchonetes, trilhas sinalizadas e guias qualificados e os recursos humanos estão entre os pontos críticos. O Instituto Chico Mendes de Conservação da Biodiversidade (ICMBio), responsável pela gestão das UC instituídas pela União, dispõe de aproximadamente dois mil funcionários para gerir 75 milhões de hectares, divididos em 313 unidades de conservação federais (ICMBIO, 2013). Em 2010 o Brasil dispunha um funcionário para cada 18,6 mil hectares de áreas protegidas. Na África do Sul esta proporção era de um servidor para cada 1,1 mil hectare e nos EUA um para cada 2,1 mil hectares. No mesmo ano o Brasil investia $R \$ 4,43$ para cada hectare de área protegida, valor muito inferior ao investido pela África do Sul $(\mathrm{R} \$ 67,09)$ e pelos Estados Unidos $(\mathrm{R} \$ 156,12)$ (MEDEIROS et al., 2011).

Frente ao baixo investimento para implementação das unidades de conservação federais de modo que cumpram os objetivos de sua criação, em entrevista ao jornal $O$ Globo, Roberto Vizentin, presidente do ICMBio, indica como soluções, além de maior orçamento, projetos de cooperação internacional, entrada de mais recursos via compensação ambiental, ampliação de parcerias com estados, municípios e órgãos como o SEBRAE e concessão de serviços à iniciativa privada (O GLOBO, 2013a; ICMBIO, 2013). Este último item, a concessão, assim como a permissão, a autorização e a gestão compartilhada com Organizações Sociais com Interesse Público (OSCIP) são instrumentos de gestão que possibilitam ao Estado viabilizar o uso público nas UCs delegando a terceiros a prestação de serviços de apoio à visitação. Os diferentes instrumentos podem proporcionar a participação de populações locais, de organizações não governamentais e da iniciativa privada (RODRIGUES, 2009) ${ }^{9}$.

Em estudo recente, Rodrigues (2009) constatou que, no caso dos parques nacionais brasileiros, todavia é incipiente a prestação de serviços por terceiros, tanto no que se refere a sua formalização quanto à diversidade e abrangência das modalidades de delegação. Porém, observa-se que dentre estes instrumentos a concessão 
tem despertado especial interesse, uma vez que pode contar com maiores investimentos da iniciativa privada. Em entrevista ao jornal O Globo, Vinícius Lummertz, secretário nacional de Políticas de Turismo do Ministério do Turismo afirma:

\begin{abstract}
Os parques com maior investimento são aqueles onde existem concessões. Nos EUA, por exemplo, estas parcerias levantam US\$ 155 bilhões. É um negócio. Aqui, ainda estamos aprendendo. $\mathrm{O}$ Parque da Tijuca já recebe $R \$ 50$ milhões da iniciativa privada. Adotando este caminho, não precisamos destinar para o turismo os recursos que poderiam ir para a educação ou para a saúde $(O$ GLOBO, 2013a, s/p).
\end{abstract}

Em suma, transparece na fala do secretário o interesse pela concessão enquanto negócio, para a qual utiliza argumentos referentes a crescimento econômico, e não exatamente como projeto social de desenvolvimento local a partir das UCs. Os parques nacionais estão incluídos nas políticas públicas do Ministério do Turismo e destacados no Plano Nacional do Turismo, que estabelece metas para tornar o Brasil o terceiro maior mercado turístico mundial até 2022 - atualmente ele é o sexto (MINISTÉRIO DO TURISMO, 2013). De acordo com o ICMBio, o número de visitantes nos parques está crescendo em média 10\% ao ano (O GLOBO, $2013 b)$, tornando-se mais atraentes para tais investimentos via concessões. Ainda que possam contribuir para a gestão das UCs, esta opção concentra os benefícios econômicos nas empresas concessionárias. A contribuição para o desenvolvimento local, nestes casos, se dá na forma de complementação aos serviços, prestação de mão de obra, entre outros.

De acordo com Rodrigues (2009), a prestação de serviços por terceiros impulsiona a apropriação mercadológica em diversas escalas com a valoração econômica das UCs. No entanto, é possível que esta prestação seja diversificada no que diz respeito à contratação de serviços de micro e pequeno porte e com a participação de organizações da sociedade civil (RODRIGUES, 2009). Sendo as populações locais as mais afetadas por impactos negativos resultantes da criação de unidades de conservação, quando alteram práticas econômicas e culturais, e considerando-se o papel destas no desenvolvimento local, também os impactos positivos poderiam ser localmente mais expressivos, via um turismo de base comunitária em alternativa ao turismo convencional.

Segundo Kinker (2005), o desafio para desenvolver o turismo nas UC brasileiras está em descobrir um modelo próprio: ainda que exemplos e experiências de outros países possam trazer ensinamentos não é viável uma padronização, pois cada região do país, suas realidades e unidades de conservação são peculiares. 


\section{Turismo de base comunitária e justiça ambiental}

As unidades de conservação, na medida em que protegem em seus limites e entorno potenciais atrativos naturais e culturais, podem estimular o desenvolvimento territorial a partir do ecoturismo. Porém, de acordo com Barreto (2000, p.23), "o crescimento do turismo tem ocorrido ao sabor do mercado, dos interesses dos grandes capitais nacionais e internacionais sem levar em conta os demais atores sociais, e sem a participação das comunidades afetadas". Em concordância, Coriolano (2006, s/p) afirma que "O modelo de turismo adotado pelos grandes empreendedores e governos neoliberais objetiva acumular lucros e divisas, por isto não cumpriu, e provavelmente não cumprirá as promessas de gerar emprego e distribuir renda para todos. Estas ideias vão ficando nos discursos, não chegam às políticas". Assim, a terceirização de serviços turísticos em unidades de conservação pode seguir este modelo convencional, privilegiando médios e grandes empresários, ou valorizar e inserir as populações locais neste processo.

A concessão de serviços é o instrumento de terceirização mais conhecido, principalmente devido à experiência do Parque Nacional do Iguaçu, "Contudo, ao mesmo tempo em que o parque é citado como exemplo, é tratado como um 'caso à parte', em função do elevado fluxo de visitantes e das estruturas condizentes com essa demanda" (RODRIGUES, 2009, p.310). Segundo Rodrigues (2009), o pouco uso e conhecimento a respeito de modalidades como permissão, autorização e parcerias com OSCIP dificulta a inserção de micro e pequenos empreendimentos de base comunitária, "[...] que podem atender a uma menor demanda de visitantes, não requerem investimentos de grande porte e fortalecem a cadeia produtiva do turismo no local' (RODRIGUES, 2009, p.310).

Para Irving (2009), além do conteúdo econômico e social, desenvolvimento local inclui a valorização da cultura, dos modos de vida, das tradições e das cosmologias locais, uma vez que é no espaço simbólico do lugar turístico que identidades se encontram e são intercambiadas. A esta proposta vincula-se o turismo de base comunitária (TBC), capaz de contribuir para a consolidação ética das dimensões do trabalho, social, política, cultural e humana e da própria expressão da dimensão simbólica da vida em sociedade (IRVING, 2009). A este entendimento acrescenta-se ainda a dimensão ambiental, que dá suporte a todas as demais.

No TBC os moradores são ao mesmo tempo articuladores e construtores da cadeia produtiva do turismo. Organizados de forma coletiva ou em núcleos familiares, prestam diferentes serviços aos turistas e são os maiores beneficiários: a renda e o lucro permanecem na comunidade, os atores sociais locais se envolvem diretamente nas atividades e há maior valorização cultural. Os empreendimentos turísticos solidários, como associações e cooperativas, surgem em um momento de resistência e ressignificação das formas de cooperação, em variados contextos de histórias, lugares e personagens, tornando única cada qual destas iniciativas.

Considerando-se que os serviços ambientais gerados pelas UCs podem ser estendidos globalmente, mas sendo as populações locais as impactadas diretamente 
por restrições da legislação ambiental, promover o TBC em unidades de conservação vai ao encontro do conceito de justiça ambiental, uma corrente do movimento ambientalista.

O movimento ecologista ou ambientalista global permanece dominado por duas principais correntes: "o culto ao silvestre" e o "evangelho da ecoeficiência", porém, é crescente uma terceira corrente chamada "ecologismo dos pobres", "ecologismo popular" ou "justiça ambiental" (MARTíNEZ ALIER, 2012, p.21). De acordo com Martínez Alier, o culto ao silvestre ou ao mundo selvagem preocupa-se com a preservação da natureza silvestre e respalda-se na biologia da conservação. Atenta-se para o crescimento populacional, mas não se pronuncia sobre a indústria ou a urbanização, mantendo-se indiferente ou em oposição ao crescimento econômico.

A segunda linha predominante, e cada vez em maior evidência, o "credo da ecoeficiência", defende o desenvolvimento sustentável, uso prudente dos recursos naturais e controle de contaminações na indústria, agricultura, pesca e silvicultura. Respalda-se na economia ambiental e na ecologia industrial para defender sua crença em novas tecnologias e na internalização das externalidades ambientais como instrumentos voltados à modernização ecológica. Aliada a esta corrente encontra-se a chamada economia verde, tratada recentemente na Rio+20, a qual, sem propor uma nova forma de relação com a natureza, e no sentido contrário, faz da emergente consciência quanto aos limites dos recursos naturais um negócio, o capitaliza.

Já a terceira corrente, o movimento pela justiça ambiental, ecologismo popular ou ecologismo dos pobres, origina-se nos conflitos ambientais pelo uso de água e de florestas ou a respeito das cargas de contaminação, por exemplo. Tais conflitos acontecem de nível local a global e, sendo gerados pelo crescimento econômico e pela desigualdade social, envolvem questões estudadas pela ecologia política. Ressalta-se que nesta corrente o discurso ambientalista nem sempre é utilizado pelos atores envolvidos, razão determinante para que até os anos 1980 não tenha sido identificada como corrente do ecologismo (MARTíNEZ ALIER, 2012). Ao encontro desta corrente segue a economia ecológica, na medida em que propõe uma escala ótima, a escala sustentável que corresponde ao máximo de economia compatível com a disponibilidade de recursos da natureza (ar, água, solo, minérios, fotossíntese etc.) e com sua capacidade de resiliência. Para defini-la é preciso indagar o que é que se deseja sustentar, qual tipo de sociedade e modelo de consumo, e em que escala de tempo (CAVALCANTI, 2012), ou seja, é preciso optar por qual sentido de desenvolvimento se pretende seguir.

Sendo que o crescimento econômico implica maiores impactos no meio ambiente, esta corrente observa que há um deslocamento geográfico das fontes de recursos naturais e das áreas de descarte dos resíduos: os impactos são desiguais quando as áreas são habitadas por ricos ou pobres, brancos ou minorias étnicas. Os países industrializados crescentemente demandam importações de matérias primas e bens de consumo, avançando a fronteira em direção a territórios do Sul, fornecedores de minérios, alimentos, petróleo, etc., e no caso das UCs, produção de bens e serviços estendidos globalmente. Resultam-se impactos não solucionados pelas políticas econô- 
Turismo de base comunitária em Unidades de Conservação: justiça ambiental para o desenvolvimento local

micas ou inovações tecnológicas, atingindo dessa maneira grupos sociais que por vezes resistem e protestam em defesa de seus direitos. Nesta terceira corrente o principal não é a reverência sagrada à natureza, mas um interesse material pelo meio ambiente para a própria subsistência, ainda que existam tradições em alguns países que se preocupam com a preservação de áreas naturais, tal qual ocorre na Índia (MARTíNEZ ALIER, 2012).

Nos Estados Unidos a luta por justiça ambiental é um movimento social organizado contra casos locais de racismo ambiental e pode-se afirmar que, neste contexto, o movimento por justiça ambiental é produto estadunidense. Diversos projetos sociais no país discutem a contaminação do ar, da pintura com chumbo, dos centros de transferência do lixo municipal, dos dejetos tóxicos, entre outros, que se concentram em bairros pobres ou habitados por minorias raciais. Como movimento organizado a justiça ambiental permaneceu limitada ao país de origem até recentemente, ainda que o ecologismo dos pobres ou ecologismo popular constituam denominações de movimentos do Terceiro Mundo contra impactos ambientais que ameaçam os pobres, por sua vez, a maioria da população em muitos países (MARTÍNEZ ALIER, 2012).

Segundo o historiador indiano Ramachandra Guha, o que acontece em seu país contraria as teses convencionais das ciências sociais ocidentais, que se baseiam em pontos de vista tal como do autor norte americano Lester Thurow, para quem os indivíduos que apoiam o ambientalismo são oriundos da classe média-alta. Guha (1994) afirma que para Thurow e muitos outros autores o ecologismo é um fenômeno social pósmaterialista, de pessoas com estômago cheio, uma inquietude de luxo e de tempo de ócio que surge somente quando as necessidades materiais básicas estão satisfeitas. No entanto, o que se observa em países como o Brasil, Índia e Quênia indica que os países pobres, e especialmente os grupos de pessoas pobres, podem também ser ecologistas, porém as motivações e formas de expressão são distintas do ambientalismo pósmaterialista chamado por Martínez Alier de ecologia da abundância, característico das sociedades avançadas industriais do Norte (GUHA, 1994).

No Brasil movimentos sociais bem constituídos também ambientalizam as questões de seus grupos, tal como ocorrido na luta dos seringueiros liderados por Chico Mendes nos anos 1980 e da mesma forma como acontece no Movimento de Atingidos por Barragens (MAB), o qual acusa o setor elétrico de rentabilizar seus investimentos pela expropriação do ambiente dos atingidos, e no Movimento dos Trabalhadores Rurais Sem-Terra (MST), ao sustentar que "não é 'produtiva' a terra que produz qualquer coisa a qualquer custo, acusando a grande agricultura químico-mecanizada de destruir recursos em fertilidade e biodiversidade, e, assim, descumprir a função social da propriedade" (ACSELRAD, 2010, p. 106). São, portanto, conflitos que nascem da crescente utilização do ambiente natural devido à expansão econômica, que avançam e causam atritos em territórios já habitados por outras pessoas e espécies.

Quanto às unidades de conservação seu objetivo principal é a proteção ambiental, não a exploração econômica. Porém, a necessidade de criação destes espaços insere-se num contexto global de crise socioambiental, resultado das demandas crescentes da população humana, as quais implicam ameaças à diversidade biológica sem precedentes (PRIMACK; RODRIGUES, 2002). O modelo de desenvolvimento hegemônico avança sobre os territórios em busca da acumulação de capital e da maximização da taxa de lucro em curto prazo. Com isto, seus padrões tecnológicos de uso, ritmos de exploração da na- 
tureza e formas de consumo geram efeitos de desequilíbrio ambiental e desigualdade social (LEFF, 2007). Neste cenário de degradação, a instituição de UCs visa à preservação de amostras significativas de ecossistemas nestes territórios. Porém, não confronta o modelo de desenvolvimento que está na raiz desta crise e desta forma, de modo geral, o estabelecimento das UCs pressiona desigualmente os grupos sociais, seja pela simples ocupação de seus ambientes, seja pela interferência em sua reprodução social. A injustiça ambiental, então, se acentua na medida em que o uso turístico de UCs públicas favorece grupos externos e minoritários, como nos casos das grandes concessões, em detrimento do incentivo à organização do turismo de base local.

Para Acselrad (2010), o fato é que enquanto os males ambientais puderem ser transferidos para os mais pobres a pressão geral sobre o ambiente não cessará. Para o autor, a questão de justiça ambiental brasileira propõe a junção estratégica entre justiça social e proteção ambiental, na medida em que sejam interrompidos os mecanismos de transferência dos custos ambientais do desenvolvimento para os mais vulneráveis.

\section{Considerações finais}

O incentivo ao turismo de base comunitária como modelo de turismo nas unidades de conservação, sob a ótica da justiça ambiental e do desenvolvimento territorial, vai ao encontro do que considera Martins (2002 apud SCHNEIDER; PEYRÉ TARTARUGA, 2004), para o qual é difícil reconhecer a legitimidade de um modelo de desenvolvimento que exclui inumeráveis seres humanos das oportunidades de participação não só nos frutos como também na produção da riqueza. A partir dessa concepção, a promoção do turismo nas UCs pode favorecer a sociedade local ao inseri-la na organização e prestação de serviços turísticos a partir dos recursos, genéricos e específicos, encontrados no próprio território, como seus atrativos naturais e culturais.

De acordo com Acselrad (2010), no movimento da justiça ambiental os atores desse ecologismo contestatório tentam preservar o espaço da crítica ambientalista ao modelo de desenvolvimento e fazer com que a questão ambiental integre um projeto político contra-hegemônico. Nesta perspectiva, as lutas entre os que querem usufruir da exploração de um recurso natural, a serviço da economia comercial-industrial crescente, e as comunidades que tiveram o controle sobre tais recursos, e cujos usos eram menos intensivos em gasto energético e de capital, podem ser consideradas como expressão de um novo tipo de conflitos de classe. Em tal disputa o objeto são os recursos naturais como florestas e a água, desejados por todos, porém cada vez mais monopolizados por alguns. No entanto, na maioria das vezes as iniciativas privadas de exploração têm a preferência e são beneficiadas pelo Estado, sobrando apenas a resistência como alternativa às populações desfavorecidas nessa disputa desigual (GUHA, 1994).

Considera-se que o desenvolvimento local só é possível quando seus habitantes estão envolvidos com autonomia, sendo anteriormente necessário, portanto, o desenvolvimento destes indivíduos, no que Amartya Sen denomina "desenvolvimento como liberdade". Segundo o autor (SEN, 2000, p.26), "Com oportunidades sociais adequadas, os indivíduos podem efetivamente moldar seu próprio destino e ajudar uns aos outros. Não precisam ser vistos, sobretudo como beneficiários passivos de engenhosos programas de desenvolvimento". Desta maneira, o turismo de base comunitária em unidades de conservação pode demandar mais tempo e trabalho para surtir efeitos positivos, no entanto, a- 
lém de mais justo ambientalmente, apresenta melhores possibilidades de sustentabilidade no longo prazo.

Se o potencial ambiental de uma região é determinado pelos diferentes processos produtivos ali encontrados, e não apenas por sua estrutura ecossistêmica (LEFF, 2007), desenvolver as pessoas, suas habilidades e capacidades, pode então ser considerado como importante passo a ser dado rumo ao desenvolvimento como um todo. Sendo assim, o incentivo ao turismo em unidades de conservação pode ter alcances mais sustentáveis ao promover aquele de base local e comunitária, fazendo com que as populações produzam e desfrutem por si próprias as riquezas a partir dos recursos de seus territórios, os quais abrangem integralmente sua natureza e sua cultura.

\section{Referências bibliográficas}

ACSELRAD, H. Ambientalização das lutas sociais: o caso do movimento por justiça ambiental. Estudos Avançados, v. 24, n. 68, p. 103-119, 2010.

BARRETO, M. Turismo e legado cultural: as possibilidades do planejamento. Campinas: Papirus, 2000.

BRASIL. Diretrizes para uma política nacional de ecoturismo. Brasília: EMBRATUR, 1994.

BRASIL. Lei N 9.985, de 18 de julho de 2002 e Decreto 4.340, de 22 de agosto de 2002. Brasília: Ministério do Meio Ambiente/ Secretaria de Biodiversidade e Florestas, 2004. v. 77.

CAVALCANTI, C. Sustentabilidade: mantra ou escolha moral? Uma abordagem ecológicoeconômica. Estudos Avançados, v. 26, n. 74, p. 35-50, 2012.

CORIOLANO, L. N. M. T. Reflexões sobre o turismo comunitário. Disponível em: <http:// www.etur.com.br/conteudocompleto.asp?idconteudo=11164>. Acesso em: 10 out. 2011.

DOUROJEANNI, M.J.; PÁDUA, M.T.J. Biodiversidade: a hora decisiva. Curitiba: UFPR, 2007.

FURTADO, C. O mito do desenvolvimento econômico. Rio de Janeiro: Paz e Terra, 1974.

FURTADO, C. Os desafios da nova geração. Revista de Economia Política, v. 24, n. 96, p. 483-486, 2004.

GUHA, R. El ecologismo de los pobres. Cuadernos de debate internacional: ecologia política, n. 8, p. 137-151, 1994.

ICMBIO. Presidente destaca esforço na gestão dos parques. Disponível em: $<$ http://www.icmbio.gov.br/portal/comunicacao/noticias/4-destaques/4142-presidente-

destaca-esforco-na-gestao-dos-parques.html>. Acesso em: 28 jul. 2013.

IRVING, M.A. Reinventando a reflexão sobre turismo de base comunitária: inovar é possível? In: BARTHOLO, R.; SANSOLO, D. G.; BURSZTYN, I. (ORGS). (Org.). Turismo de Base Comunitária: diversidade de olhares e experiências brasileiras. Rio de Janeiro: Nova Letra, 2009. . 
Betti, P.; Denardin, V.F.

KINKER, S. Ecoturismo e conservação da natureza em parques nacionais. Campinas: Papirus, 2005.

LEFF, E. Epistemologia ambiental. São Paulo: Cortez, 2007.

LEUZINGER, M.D. Natureza e Cultura: direito ao meio ambiente equilibrado e direitos culturais diante da criação de unidades de conservação de proteção integral e domínio público habitadas por populações tradicionais. 2007. Tese de Doutorado. Centro de Desenvolvimento Sustentável. UnB, 2007.

LEUZINGER, M.D. Uso público em unidades de conservação. 2010, Rio de Janeiro: $8^{\circ}$ Anais do Congresso do Magistério Superior de Direito Ambiental da APRODAB e $01^{\circ}$ Congresso de Direito Ambiental da PUC-Rio, 2010. p. 1-19.

MARTÍNEZ ALIER, J. Ecologismo dos pobres. São Paulo: Contexto, 2012.

MEDEIROS, R. et al. Contribuição das unidades de conservação para a economia nacional: Sumário Executivo. Brasília: UNEP-WCMC, 2011.

MINISTÉRIO DO TURISMO. Plano nacional de turismo 2013 - 2016. . [S.I: s.n.], 2013. Disponível em: <http://www.turismo.gov.br/turismo/o ministerio/plano nacional/>.

MMA. Diretrizes para visitação em unidades de conservação. Brasília: MMA: [s.n.], 2006.

O GLOBO. Brasil tem perda bilionária em setor turístico. 15 jul. 2013a. Disponível em: $<$ http://oglobo.globo.com/ciencia/brasil-tem-perda-bilionaria-em-setor-turistico-

9021526\#ixzz2Z9R1MuGX >.

O GLOBO. Parques nacionais oferecem natureza para poucos. 13 jul. 2013b. Disponível em: <http://oglobo.globo.com/ciencia/parques-nacionais-oferecem-natureza-parapoucos-9020694\#ixzz2Z9CcEJlq $>$.

PECQUEUR, B. Qualidade e desenvolvimento territorial: a hipótese da cesta de bens e de serviços territorializados. Eisforia, v. 4, p. 81-103, dez. 2006.

PRIMACK, R. B.; RODRIGUES, E. Biologia da Conservação. Londrina: Vida, 2002.

RODRIGUES, C.G.O. O uso do público nos parques nacionais : a relação entre as esferas pública e privada na apropriação da biodiversidade. Tese (Doutorado em Desenvolvimento Sustentável) - Centro de Desenvolvimento Sustentável, Universidade de Brasília, Brasília: [s.n.], 2009.

SCHNEIDER, S.; PEYRÉ TARTARUGA, I.G. Território e abordagem territorial: das referências cognitivas aos aportes aplicados à análise dos processos sociais rurais. Raízes, v. 23, n. 01 e 02, p. 99-117, 2004.

SEN, A. Desenvolvimento como liberdade. São Paulo: Companhia das Letras, 2000.

\section{Agradecimento:}

Agradecemos à CAPES pela bolsa de estudos e à FINEP/MTur - Projeto Turismo e Economia Solidária no Paraná. 


\section{Notas:}

1 Todo e qualquer procedimento que vise assegurar a conservação da diversidade biológica e dos ecossistemas. (Lei 9.985, de 18 de julho de 2000).

${ }^{2}$ Documento técnico mediante o qual, com fundamento nos objetivos gerais de uma unidade de conservação, se estabelece o seu zoneamento e as normas que devem presidir o uso da área e o manejo dos recursos naturais, inclusive a implantação das estruturas físicas necessárias à gestão da unidade (Lei 9.985, de 18 de julho de 2000).

${ }^{3}$ Neste grupo incluem-se: Área de Proteção Ambiental, Reserva Extrativista, Reserva de Desenvolvimento Sustentável, Floresta Nacional, Reserva Particular do Patrimônio Natural, Área de Relevante Interesse Ecológico e Reserva de Fauna (Lei 9.985, de 18 de julho de 2000).

${ }^{4}$ Neste grupo incluem-se: Parque Nacional, Estação Ecológica, Reserva Biológica, Monumento Natural e Refúgio de Vida Silvestre (Lei 9.985, de 18 de julho de 2000).

${ }^{5}$ Com exceção dos casos previstos na Lei Federal $n^{\circ}$ 9.985, de 18 de setembro de 2000.

${ }^{6} \mathrm{O}$ território pode ser definido como "uma construção social de um grupo combinado, por vezes provisório, estruturado em torno de recursos compartilhados. Com muita frequência, esses recursos estão ligados a (ou oriundos de) um espaço físico bem delimitado." (PECQUEUR, 2006, p. 149).

${ }^{7}$ O aproveitamento e a utilização da Unidade de Conservação com fins recreacionais, educativos, entre outras formas de utilização indireta dos recursos naturais e culturais (MMA, 2006, p. 9).

${ }^{8}$ Instrumento que impõe ao empreendedor a obrigatoriedade de apoiar a implantação e manutenção de unidade de conservação do grupo de proteção integral, quando, durante o processo de licenciamento e com fundamento em estudo de impacto ambiental e seu respectivo relatório, um empreendimento for considerado como de significativo impacto ambiental.

${ }^{9}$ Para discussão aprofundada a respeito da dinâmica na prestação de serviços em UC por terceiros e tais instrumentos de gestão ver Rodrigues (2009).

Patrícia Betti: Universidade Federal do Paraná, Curitiba, PR, Brasil.

Email: patibetti@gmail.com

Link para o currículo Lattes: http://lattes.cnpq.br/5008270042129060

Valdir Frigo Denardin: Universidade Federal do Paraná, Curitiba, PR, Brasil.

Email: valdirfd@yahoo.com.br

Link para o currículo Lattes: http://lattes.cnpq.br/0290714285197089

Data de submissão: 29 de julho de 2013

Data de recebimento de correções: 29 de junho de 2013

Data do aceite: 01 de setembro de 2013

Avaliado anonimamente 